\title{
Diclofenac versus tramadol for mucositis related pain in head and neck cancer patients undergoing concurrent chemoradiation-a phase 3 study
}

\author{
Amit Joshi ${ }^{1, \dagger}$, Vijay Maruti Patil ${ }^{1, \dagger}$, Vanita Noronha ${ }^{1, \dagger}$, Atanu Bhattacharjee ${ }^{2}$, Nandini Menon ${ }^{1}$, Amit Kumar ${ }^{1, \dagger}$, Parmanand Jain ${ }^{3}$, \\ Sadaf Mukadam ${ }^{1}$, Avadhoot Shrinivas ${ }^{1}$, Anjali Punia ${ }^{1}$, Anuja Abhyankar ${ }^{1}$, Amit Agarwal ${ }^{1}$, Satvik Khaddar ${ }^{1}$, Anu Rajpurohit ${ }^{1}$, \\ Kanteti Aditya Pavan Kumar ${ }^{1}$, Rahul Ravind ${ }^{1}$, Kishore Das ${ }^{1}$, Vikas Talreja ${ }^{1}$, Sachin Dhumal ${ }^{1}$ and Kumar Prabhash ${ }^{1}$
}

${ }^{1}$ Department of Medical Oncology, Tata Memorial Centre, HBNI, Mumbai, 400012, India

${ }^{2}$ Section of Biostatistics, Centre for Cancer Epidemiology, Tata Memorial Centre, Navi-Mumbai, 410210, India

${ }^{3}$ Pain Clinic, Department of Anesthesia, Tata Memorial Centre, HBNI, Mumbai, 400012, India

tThese authors contributed equally

\begin{abstract}
Background: Oral mucositis related pain during CTRT in head and neck cancers is a common problem. Unfortunately, in spite of it being common, there is limited evidence for selection of systemic analgesic in this situation. Hence, this study was designed to compare the analgesic effect of a non-steroidal anti-inflammatory drug (diclofenac) versus a weak opioid (tramadol).
\end{abstract}

Patients and methods: This was an open-label, parallel design, superiority randomised controlled study. In this study, head and neck cancer patients undergoing radical or adjuvant chemoradiation, who had grade 1 or above mucositis (in accordance with Common Terminology Criteria for Adverse Events version 4.03) and had pain related to it were randomly assigned to either diclofenac or tramadol for mucositis related pain control. The primary endpoint was analgesia after the first dose. The secondary endpoints were the rate of change in analgesic within 1 week, adverse events and quality of life.

Results: One hundred and twenty-eight patients were randomised, 66 in diclofenac and 62 in tramadol arm. The median area under the curve for graph of pain across time after first dose of pain medication for the diclofenac arm and the tramadol arm was 348.936 units (range: 113.64-1,969.23) and 420.87 (101.97-1,465.96), respectively, $(p=0.05619)$. Five patients $(8.1 \%)$ in the tramadol arm and 11 patients $(16.7 \%)$ in the diclofenac arm required a change in analgesic within 1 week of starting the analgesic $(p=0.184)$. There was no statistically significant difference in any adverse events between the two arms. However, the rate of any grade of renal dysfunction was numerically higher in the diclofenac arm $(10.6 \%$ versus $4.8 \%, p=0.326)$.

Conclusion: In this phase 3 study, evaluating diclofenac and tramadol for chemoradiation induced mucositis pain, there was no statistical difference in analgesic activity of these two drugs.

Keywords: pain, oral mucositis, head and neck, chemoradiation, diclofenac, tramadol
Correspondence to: Kumar Prabhash Email: kumarprabhashtmh@gmail.com ecancer 2021, 15:1318 https://doi.org/10.3332/ecancer.2021.1318

Published: 18/11/2021 Received: 11/04/2021

Publication costs for this article were supported by ecancer (UK Charity number 1176307).

Copyright: $($ ) the authors; licensee ecancermedicalscience. This is an Open Access article distributed under the terms of the Creative Commons Attribution License (http:// creativecommons.org/licenses/by/4.0), which permits unrestricted use, distribution, and reproduction in any medium, provided the original work is properly cited. 


\section{Introduction}

Mucositis is common in head and neck cancer patients undergoing concurrent chemoradiation [1]. The overall incidence of any grade mucositis ranges between $65.3 \%$ and $96.9 \%$, while the incidence of grade 3 and above mucositis is between 17.3\% and 55.8\% [1, 2]. Mucositis commonly becomes symptomatic between the second and fourth week of treatment and is associated with considerable pain [3]. Mucositis induced pain leads to decreased oral intake, which in turn impairs the nutritional intake, leads to radiation interruption or dose modification and it negatively impacts the patient's quality of life [3-5].

Management of mucositis related pain is an important component of the treatment of mucositis [6-8]. Both local and systemic analgesia are required for treatment. However, the literature on analgesia for mucositis related pain is vastly concentrated on the use of local analgesics [9]. Use of local rinse consisting of anaesthetic with diphenhydramine $\&$ antacid [10], doxepin mouth rinse [10, 11], amitriptyline mouth rinse [12] and diclofenac mouth rinse [13] are all associated with pain relief. Although commonly used, whether these local rinses are associated with a clinically meaningful decrease in pain is an open question [9, 10, 14]. In practice, systemic adjuvants are commonly used for mucositis related pain [15-17].

The World Health Organization (WHO) pain ladder is commonly used to guide the selection of systemic analgesics [18-20]. Non-steroidal anti-inflammatory drugs (NSAIDs) are the recommended first analgesics in accordance with the WHO ladder. In addition to the analgesic effect, these agents also have an anti-inflammatory property which is an added attraction for their use in mucositis. Weak and strong opioids are other options for the management of mucositis related pain [15]. The choice between diclofenac and tramadol seems obvious; the NSAID would be used initially and then tramadol if analgesia is uncontrolled as per the WHO ladder [18]. However, non-selective NSAIDs like diclofenac have a tendency for causing renal side effects [22, 23]. Cisplatin is the commonest agent used for radiosensitisation in head and neck cancer and can cause derangement in renal function [24]. Further, systemic use of selective-NSAID like celecoxib has failed to relieve mucositis related pain in a phase 3 study [25]. However, diclofenac is a non-selective NSAID which has shown better analgesic properties than celecoxib in a different clinical scenario [26]. Hence, we planned a phase 3 study with the hypothesis that the analgesic effect of systemically administered diclofenac would be better than tramadol in mucositis associated pain.

\section{Methods}

\section{Study conduct and trial design}

This was an open-label, parallel-arm, superiority, pragmatic, phase 3, randomised study conducted at Tata Memorial Centre, Mumbai, India. The study protocol was approved by the Institutional Ethics Committee. The trial was registered prospectively with the Clinical Trial Registry of India (CTRI/2016/09/007302 (Registered on 23/09/2016)). It was conducted in accordance with the guidelines for Good Clinical Practice - International Conference on Harmonisation E6(R2), Declaration of Helsinki and Indian Council of Medical Research guidelines. All patients provided written informed consent prior to participation. The study was funded by an intramural grant from the Tata Memorial Center Research Administration Council (TRAC). The funding agency had no role in design and conduct of the study, collection, management, analysis and interpretation of the data, preparation, review or approval of the manuscript, and decision to submit the manuscript for publication. The study protocol (Version 2.0, Dated 28 February 2016) had no amendments post its initial approval and the investigators adhered to the approved study protocol.

\section{Participants}

Adult (age $\geq 18-70$ years) head and neck cancer patients who were undergoing concurrent chemoradiation were invited to participate in the study subject to fulfilment of below-mentioned eligibility criteria. The planned dose of radiation had to be $60 \mathrm{~Gy}$ or above and administered in a conventional fashion, 1.8-2 Gy per fraction with radiation delivery 5 days a week. Patients with Eastern Cooperative Oncology Group (ECOG) Performance Status (PS) 0-2, with adequate haematological and liver functions, with mucositis related pain of 1 or more on the visual analogue scale (VAS) were invited for the study. Patients who were already on analgesic or had deranged serum creatinine (>1.5 upper limits of normal) or had an allergy to study medications were excluded. 


\section{Randomisation}

Patients were randomised in a 1:1 fashion between the two arms. The random allocation sequence was generated by an independent statistician. The allocation was performed by block stratified randomisation. The factors considered for stratification were the site of the tumour (oral versus others), T grouping (T1-2, T3-4), N grouping (N0-N1, N2-N3) and pain score on VAS (below 5 versus 5 or above). Sixteen strata were generated with each having a block size of 4 . The study investigators or coordinators did not have access to the randomisation sheets and it was performed by an independent person.

\section{Interventions}

The study had two interventional arms, arm A and arm B. Patients in arm A received tablet diclofenac for pain relief. Diclofenac was administered in a dose of $50 \mathrm{mg}$ per os (PO) thrice daily (TID). Patients in arm B received tablet tramadol for pain relief. Tramadol was administered in a dose of $50 \mathrm{mg}$ PO TID. All patients in both arms received a local rinse with local anaesthetic (benzocaine $20 \% \mathrm{w} / \mathrm{w}$ ) and antacid (aluminium hydroxide, magnesium topical and oxetacaine topical) in addition to the systemic analgesic. The first dose was administered under the supervision of the trial staff. Pain scores at baseline (on VAS) and at 5, 15, 30, 60, 120, 240, 300 and 360 minutes after the first dose of analgesic were noted. The VSA had a minimum score of 0 and a maximum score of 10 represented in a horizontal line with $10 \mathrm{~cm}$ separation between 0 and 10. The patients were instructed by the trial staff to plot their scores in accordance with the pain felt where 0 - represented no pain, while 10 - represented maximum bearable pain. The score at each time point was measured using a ruler (line gauge).

Subsequent follow-up were conducted weekly till completion of chemoradiation (CTRT). At each week, blood investigations inclusive of complete blood count, serum creatinine, serum electrolytes ( $\mathrm{Na}, \mathrm{K}, \mathrm{Ca}, \mathrm{Mg}$ ), serum glutamic-oxaloacetic transaminase (SGOT), serum glutamate-pyruvate transaminase (SGPT) and total bilirubin were performed. In addition, pain control, compliance with pain medications and adverse events (in accordance with Common Terminology Criteria for Adverse Events version 4.03) were assessed. Pain and analgesic effect were assessed at each visit as per the VAS. If inadequate pain control was noted, then the patient's analgesic was changed. The definition of inadequate pain control was the presence of pain of 1 or more on VAS. This change was done with the discussion and concurrence of two clinicians. The pattern of change of analgesic was predefined. In case of inadequate pain control in the diclofenac arm, a weak opioid was added. While in case of inadequate pain control in the tramadol arm, an NSAID was added. In case of subsequent inadequate pain control in any arm after the first change, a strong opioid was considered. Quality of life questionnaire (European Organization for the Research and Treatment of Cancer Quality of Life Questionnaire (EORTC QLQ)-c30 and QLQ-HN-35) was administered to patients at baseline, at each subsequent visit till end of treatment.

\section{Sample size}

Assuming a $5 \%$ significance level, with $80 \%$ power to detect a clinically meaningful effect size of 0.5 of a standard deviation between the two arms, we required 128 patients (64 patients for each arm) based on the two-sample $t$-test with an equal-variance assumption.

\section{Outcome assessment}

The primary endpoint of the study was analgesia for 6 hours post first dose of studied analgesic.

For quantification of the analgesic effect, an area under the curve (AUC) was plotted with time being represented on the $X$-axis and pain scores on the $Y$-axis. On the $X$-axis, the time points $0,5,15,30,60,120,240,300$ and 360 minutes were represented by values $1,2,3$, $4,5,6,7,8$ and 9 to avoid overweighting the later time points. The values of $Y$-axis were plotted with the baseline score being considered as $100 \%$ and the rest of the scores were adjusted accordingly. The secondary outcomes were to compare the proportion of patients requiring a change in analgesic within 1 week of the start of studied analgesic, adverse events, weight loss and quality of life at the end of treatment. 


\section{Statistical methods}

Statistical Package for the Social Sciences version 20 and RStudio version were used for analysis. Intention to treat analysis was performed. Descriptive statistics were performed. Ordinal and nominal variables were expressed in terms of percentages with $95 \%$ confidence interval (Cl) while continuous variables were expressed in terms of the median with range. Missing data were imputed using the multivariate imputation by chained equations. The AUC for analgesia was calculated using the trapezoidal rule. The AUC was compared between the two arms using the Wilcoxon rank-sum test. The effect size index was calculated for the difference in the AUC between the two arms and interpreted as per Cohen. A $p$-value of 0.05 or below was considered as statistically significant while an effect size of 0.5 or above was considered as clinically significant. Post hoc sensitivity analysis was performed using two methods. First was comparing AUC between the two arms using the Wilcoxon rank-sum test. However, the missing data was tackled using the listwise deletion method (complete data set analysis). The second was comparing the pain scores at different time points between the two arms using Linear Mixed Effect Model. The comparison of change of analgesic within 1 week, adverse events and weight loss was performed using Fisher's test. The quality of life analysis was performed as per the European Organization for Research and Treatment of Cancer (EORTC) guidelines. The linear mixed effect was performed as an extension of the linear model to compare quality of life domains between the two treatment arms. The data were censored for analysis on 9 July 2019.

\section{Results}

\section{Baseline characteristics}

The study recruited 128 patients between 26 April 2017 and 20 May 2019, with 66 patients in diclofenac and 62 patients in tramadol arm. Figure 1 shows the consort diagram. The baseline characteristics are shown in Table 1.

\section{Analgesia within 6 hours}

Pain scores in 8 (6.25\%) patients were missing at time points at 5, 15, 30, 120, 240 and 300 minutes. While for 9 (7\%) patients, the data of pain scores at 60 and 360 minutes were missing. The pain score at different time points overall and between the two arms is shown in Figure 2 panel A \& B, respectively. The median AUC for diclofenac arm and tramadol arm was 348.9 units (range: 113.6-1,969.2) and 420.9 (102.0-1,466.0), respectively, ( $p=0.06)$ with the complete dataset method using Wilcoxon rank-sum test. The calculated Cohen effect size for this difference was 0.125 , suggesting it was not clinically significant (Supplementary Table 1 and 2). The result of post hoc sensitivity analysis done using listwise deletion method corroborated with the primary analysis. The median AUC for diclofenac and tramadol arm was 365.5 units (range: 113.6-1,969.2) and 420.9 (102.0-1,466.0), respectively, $(p=0.11$ ) with the listwise deletion method using Wilcoxon rank-sum test. The sensitivity analysis performed using a linear mixed effect model also confirmed the same findings (Supplementary Table 3). A post hoc analysis of average pain scores over the first 6 hours was also performed using both listwise deletion ( $p=0.46)$ and complete dataset methods $(p=0.58)$ and the results were in line with the primary analysis.

\section{Change of analgesic}

Five patients (8.1\%) in the tramadol arm and 11 patients (16.7\%) in the diclofenac arm required a change in analgesic within 1 week of starting the analgesic $(p=0.18)$ (Supplementary Figure 1). The cause of change in analgesic in all patients was inadequate pain relief. The unadjusted odds ratio for change in analgesic was 2.280 (95\% Cl: $0.744-6.989)$ in favour of tramadol arm ( $p=0.15)$. The adjusted odds ratio was 2.329 (95\% Cl: 0.69-7.855) in favour of tramadol arm ( $p=0.173)$ (Supplementary Table 2). 


\section{CONSORT Flow Diagram}

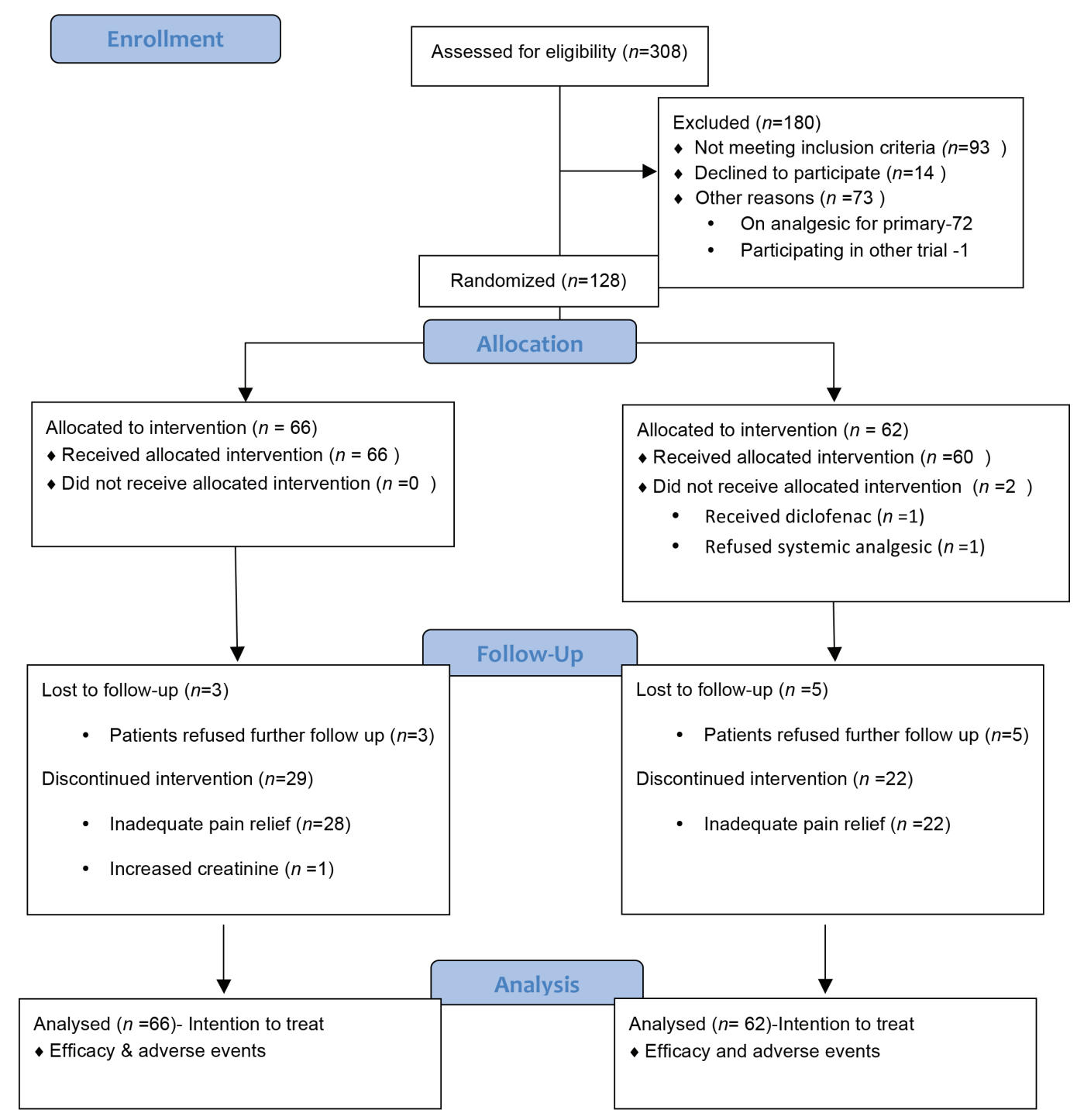

Figure 1. Consort diagram.

Twenty-nine patients (43.9\%) in the diclofenac arm and 22 patients (35.5\%) in the tramadol arm had a change in studied analgesic till the end of chemoradiation $(p=0.37)$. The cause of change in analgesic in all patients except one was inadequate pain relief. One patient in the diclofenac arm had a rise in serum creatinine and hence the analgesic was changed. The unadjusted odds ratio for change in analgesic was 1.425 (95\% Cl: 0.699-2.904; $p=0.33$ ), while the adjusted odds ratio was 1.612 (95\% Cl: 0.749-3.471; $p=0.222$ ) (Supplementary Table 2). The only factor statistically associated with a higher rate of change of analgesia at the end of treatment was the use of tobacco (odds ratio3.402; 95\% Cl: 1.067-10.847, $p=0.038$ ). Data are shown in Supplementary Table 2. 
Table 1. Baseline characteristics.

\begin{tabular}{|c|c|c|}
\hline Variable & Diclofenac arm $(n=66)$ & Tramadol arm $(n=62)$ \\
\hline Age-Median (range) in years & $52.5(28-70)$ & $48(28-70)$ \\
\hline $\begin{array}{l}\text { Gender-no (\%) } \\
\text { Male } \\
\text { Female }\end{array}$ & $\begin{array}{l}54(81.8) \\
12(18.2)\end{array}$ & $\begin{array}{l}52(83.9) \\
10(16.1)\end{array}$ \\
\hline $\begin{array}{l}\text { ECOG PS-no (\%) } \\
0-1 \\
2\end{array}$ & $\begin{array}{c}65(98.5) \\
1(1.5)\end{array}$ & $\begin{array}{c}60(96.8) \\
2(3.2)\end{array}$ \\
\hline $\begin{array}{l}\text { Tumour site-no (\%) } \\
\text { Oral } \\
\text { Oropharynx } \\
\text { Larynx } \\
\text { Hypopharynx } \\
\text { Others }\end{array}$ & $\begin{array}{c}29(43.9) \\
13(19.7) \\
10(15.2) \\
13(19.7) \\
1(1.5)\end{array}$ & $\begin{array}{c}24 \text { (38.7) } \\
21 \text { (33.9) } \\
8 \text { (12.9) } \\
9 \text { (14.5) } \\
-\end{array}$ \\
\hline $\begin{array}{l}\text { T grouping-no (\%) } \\
\text { T1-T2 } \\
\text { T3-T4 }\end{array}$ & $\begin{array}{l}10(15.1) \\
56(84.9)\end{array}$ & $\begin{array}{l}18(29.1) \\
44(70.9)\end{array}$ \\
\hline $\begin{array}{l}\text { N grouping-no (\%) } \\
\text { N0-N1 } \\
\text { N2-N3 }\end{array}$ & $\begin{array}{l}33(50) \\
33(50)\end{array}$ & $\begin{array}{l}29(46.8) \\
33(53.2)\end{array}$ \\
\hline $\begin{array}{l}\text { Stage grouping-no (\%) } \\
\text { Stage III } \\
\text { Stage IV }\end{array}$ & $\begin{array}{l}22(33.3) \\
44(66.7)\end{array}$ & $\begin{array}{l}22(35.5) \\
40(64.5)\end{array}$ \\
\hline $\begin{array}{l}\text { Indication for radiation-no (\%) } \\
\text { Definitive } \\
\text { Adjuvant }\end{array}$ & $\begin{array}{l}38(57.6) \\
28(42.4)\end{array}$ & $\begin{array}{l}41(66.1) \\
21(33.9)\end{array}$ \\
\hline $\begin{array}{l}\text { Pain score at baseline-no (\%) } \\
1-<5 \\
5-10\end{array}$ & $\begin{array}{l}31 \text { (62.1) } \\
25(37.9)\end{array}$ & $\begin{array}{l}38(61.3) \\
24(38.7)\end{array}$ \\
\hline $\begin{array}{l}\text { Comorbidities-no (\%) } \\
\text { Hypertension } \\
\text { Diabetes mellitus }\end{array}$ & $\begin{array}{l}7(10.6) \\
8(12.1)\end{array}$ & $\begin{array}{c}8(12.9) \\
5(8.1)\end{array}$ \\
\hline $\begin{array}{l}\text { Habits-no (\%) } \\
\text { Tobacco-oral } \\
\text { Tobacco-smoke } \\
\text { Alcohol }\end{array}$ & $\begin{array}{c}43(65.2) \\
23(34.8) \\
8(12.1)\end{array}$ & $\begin{array}{c}41(66.1) \\
19(30.6) \\
5(8.1)\end{array}$ \\
\hline
\end{tabular}

ECOG, Eastern Cooperative Oncology Group; PS, Performance status

The median duration of analgesic in the study was 28.5 days (range: $7-63$ ). The median time to change to analgesic was 28 days (95\% $\mathrm{Cl}$ : 18.248-37.752) for diclofenac versus 54 days (95\% Cl: 30.617-77.383) for tramadol $(p=0.18)$. Tramadol and morphine were required in the diclofenac arm in 23 (34.8\%) and 8 (12.1\%) patients, respectively. While diclofenac and morphine were required in 16 patients (25.8\%) and 7 patients (11.3\%), respectively, in the tramadol arm. 

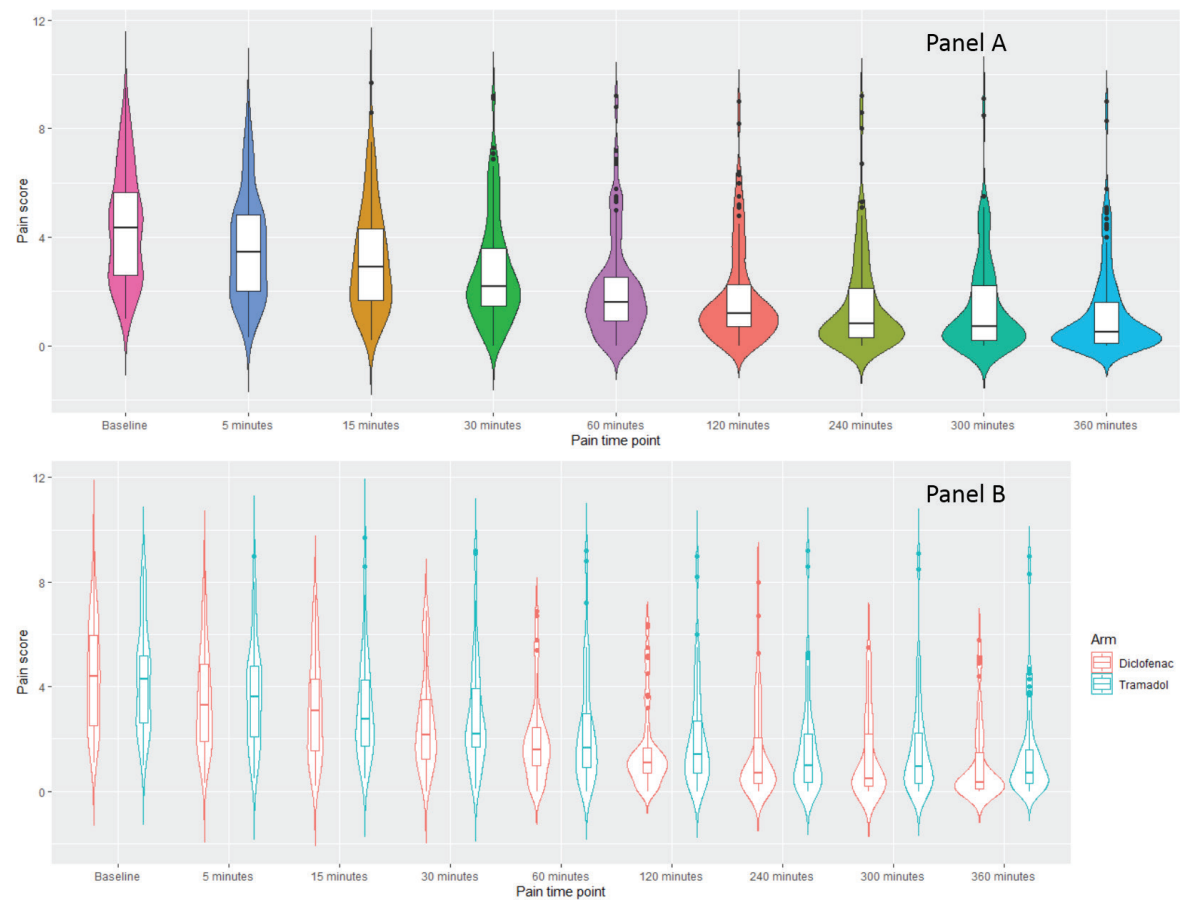

Figure 2. Violin plot depicting the pain scores at baseline at different time points till 6 hours after administration of first dose in both arms.

\section{Adverse events \& compliance}

The compliance in diclofenac and tramadol arm was observed in $55(83.3 \%)$ and $52(83.9 \%)$, respectively, $(p=1)$. The incidence of nasogastric tube insertion was $54.5 \%(36)$ and $56.5 \%$ (35) in diclofenac and tramadol arm, respectively, $(p=0.86)$. The adverse events in both arms are shown in Table 2. There was no statistically significant difference in any adverse events between the two arms. However, the rate of any grade renal dysfunction was numerically higher in the diclofenac arm (10.6\% versus $4.8 \%, p=0.33)$.

\section{Compliance with cancer-directed treatment}

The details of radiation dose planned, technique, chemotherapy planned are shown in Table 3. The radiation technique was imbalanced between both arms with a higher number of patients in the diclofenac arm were treated with three-dimensional conformal radiation therapy (3DCRT) than in the tramadol arm (18.2\% versus $1.6 \%$, Table 3$)$. There was also a difference in cumulative dose of cisplatin received between both arms. In the diclofenac arm, 49 patients $(80.3 \%, n=61)$, while in the tramadol arm 55 patients $(93.2 \%, n=59)$ received a cumulative dose of cisplatin $\geq 200 \mathrm{mg} / \mathrm{m}^{2}(p=0.06)$.

\section{Quality of life analysis}

The quality of life at baseline and at each visit was similar between both arms. The results of quality of life analysis using linear mixed effect models are shown in Supplementary Table 3. 
Table 2. Adverse event details in both arms. The numbers with percentages in brackets are depicted.

\begin{tabular}{|c|c|c|c|c|c|c|}
\hline \multirow[t]{2}{*}{ Adverse event } & \multicolumn{2}{|c|}{ Diclofenac arm $(n=66)$} & \multicolumn{2}{|c|}{ Tramadol arm $(n=62)$} & \multirow{2}{*}{$\begin{array}{l}p \text { value for any } \\
\text { grade events }\end{array}$} & \multirow{2}{*}{$\begin{array}{c}p \text { value for grade } 3 \\
\& \text { above events }\end{array}$} \\
\hline & Any grade & Grade 3-5 & Any grade & Grade 3-5 & & \\
\hline Mucositis & $66(100)$ & $23(34.8)$ & $62(100)$ & $17(27.4)$ & - & 0.47 \\
\hline Dysphagia & $60(90.9)$ & $20(30.3)$ & $56(90.3)$ & $12(19.4)$ & 1 & 0.22 \\
\hline Weight loss & $39(59.1)$ & $1(1.5)$ & $39(62.9)$ & - & 0.72 & 1 \\
\hline Nausea & $26(39.4)$ & $2(3)$ & $20(32.3)$ & $2(3.2)$ & 0.47 & 1 \\
\hline Vomiting & $17(25.8)$ & - & $18(29)$ & $2(3.2)$ & 0.7 & 0.23 \\
\hline Constipation & 7 (11.3) & - & $13(19.7)$ & - & 0.23 & - \\
\hline Rise in creatinine & $7(10.6)$ & - & $3(4.8)$ & - & 0.33 & - \\
\hline Hyponatraemia & $60(90.9)$ & $17(25.8)$ & 54 (87.1) & $17(27.4)$ & 0.58 & 0.84 \\
\hline Hypokalaemia & $4(6.1)$ & $1(1.5)$ & $8(12.9)$ & $3(4.8)$ & 0.23 & 0.35 \\
\hline Hypomagnesaemia & $22(33.3)$ & - & $28(45.2)$ & $1(1.6)$ & 0.21 & 0.48 \\
\hline SGOT rise & 9 (13.6) & $1(1.5)$ & $11(17.7)$ & $1(1.6)$ & 0.63 & 1 \\
\hline SGPT rise & $12(18.2)$ & $1(1.5)$ & $14(22.6)$ & $1(1.6)$ & 0.66 & 1 \\
\hline Anaemia & $53(80.3)$ & $3(4.5)$ & $54(87.1)$ & - & 0.35 & 0.25 \\
\hline Neutropenia & $15(22.7)$ & $6(9.1)$ & 21 (33.9) & $6(9.7)$ & 0.17 & 1 \\
\hline Thrombocytopenia & $14(21.2)$ & $2(3)$ & $15(24.2)$ & $1(1.6)$ & 0.83 & 1 \\
\hline
\end{tabular}

SGOT, Serum glutamic-oxaloacetic transaminase; SGPT, Serum glutamic pyruvic transaminase

Table 3. Chemoradiation compliance details.

\begin{tabular}{|l|c|c|c|}
\hline \multicolumn{1}{|c|}{ Variable } & Diclofenac arm $(\boldsymbol{n}=66)$ & Tramadol arm $(\boldsymbol{n}=62)$ & $p$ value \\
\hline Technique-no (\%) & $40(60.6)$ & $48(77.4)$ & 0.005 \\
Conventional & $12(18.2)$ & $1(1.6)$ & \\
3DCRT & $14(21.2)$ & $13(21)$ & \\
Intensity modulated radiotherapy & & & \\
& $28(42.5)$ & $22(35.5)$ & \\
\hline Planned dose in Gy-no (\%) & $9(13.6)$ & $5(8.1)$ & \\
60 & $29(43.9)$ & $35(56.4)$ & \\
$>60-<70$ & & $4(6.5)$ & \\
70 & - & $48(77.4)$ & \\
\hline Chemotherapy planned-no (\%) & $52(78.9)$ & $7(11.3)$ & \\
3 weekly cisplatin & $9(13.6)$ & $1(1.6)$ & \\
Weekly cisplatin & $3(4.5)$ & $1(1.6)$ & \\
Cisplatin-nimotuzumab & - & $2(3.2)$ & \\
Carboplatin & $2(3)$ & & \\
Nimotuzumab & $4(6)$ & & \\
Docetaxel & & & \\
\hline Planned radiation dose not completed- & & & \\
no (\%) & & & \\
\hline
\end{tabular}


Table 3. Chemoradiation compliance details. (Continued)

\begin{tabular}{|l|c|c|c|}
\hline Reasons for non-completion-no (\%) & & & - \\
Default & $2(3)$ & $1(1.6)$ & \\
Progression & $1(1.5)$ & - & \\
Adverse event & $1(1.5)$ & $1(1.6)$ & 0.69 \\
\hline Completed chemotherapy & $55(83.3)$ & $49(79)$ & \\
Yes & $7(10.6)$ & $10(16.1)$ & \\
No-adverse events & $4(6.1)$ & $3(4.8)$ & \\
No-patient refused & $49(80.3)^{\mathrm{a}}$ & $55(93.2)^{\mathrm{a}}$ & 0.058 \\
\hline $200 \mathrm{mg} / \mathrm{m}^{2}$ of cisplatin received-no (\%) & & & \\
\hline
\end{tabular}

${ }^{a} n$ used for the percentage calculation was 61 and 59 in diclofenac and tramadol arm, respectively. This was the number of patients who received cisplatin in both arms

\section{Discussion}

This study evaluated the role of systemic analgesia in mucositis pain. In the current study, there was a decrease in pain scores after administration of the first dose of systemic analgesic (Figure 2); however, there was no statistical difference or clinically relevant difference (as effect size was only 0.125) [27] in the efficacy of the two types of analgesics. Thus, suggesting that both tramadol and diclofenac in the doses used in the current study have a similar analgesic effect within 6 hours of the first dose. It is important for an analgesic not only to have a rapid decrement in pain but also to sustain the analgesia over the required duration. The sustenance of analgesia as suggested by proportion of patients in whom a change in analgesic was required by 1 week and by the end of treatment was also statistically similar between the two arms. Thus, implying that both diclofenac and tramadol have similar analgesic activity.

The selection of any drug, as the drug of choice, rests on adverse event profile if efficacy is similar. The adverse events were similar between both arms and were largely dictated by the adverse events related to cancer-directed therapy. However, there was a numerical difference in the rate of renal dysfunction between the two arms, with the incidence being twice in diclofenac arm than tramadol arm. The rate of renal dysfunction in the current study is overall lower than that reported in western literature and is primarily because of predominant use of weekly cisplatin $[28,29]$. Considering that there is no added advantage of diclofenac with respect to analgesia over tramadol, it might be better to avoid diclofenac especially when cisplatin regimen is used for radiosensitisation. Both diclofenac and cisplatin are known to cause renal dysfunction. Cisplatin causes disruption of the S3 segment of the proximal renal tubule [30], while NSAIDs like diclofenac lead to interstitial nephritis [31]. There seems to be an additive effect of the addition of diclofenac to cisplatin on renal dysfunction. In addition, the presence of volume depletion acts as a predisposition for renal dysfunction with both agents [31, 32]. Due to poor intake and increased insensible loss, mucositis pain is common in patients with severe mucositis. There is also evidence to suggest the development of acute kidney injury during chemoradiation in head and neck cancer patients leads to a decrease in survival [24]. Hence, it seems reasonable that NSAID should be avoided for analgesia in such patients.

The focus of research on analgesic treatment of mucositis pain is largely restricted to local analgesics [10, 11, 14]. However, in practice, a large proportion of patients irrespective of use of local analgesics require systemic analgesia including morphine [15, 17]. As was observed in the current study, $>10 \%$ of patients require morphine by the end of treatment for pain relief. Use of strong opioids like morphine leads to opioid related side effects like nausea, constipation, sedation, dry mouth which can hamper the quality of life [21]. Hence, it is important to have longitudinal data on change of analgesic, especially assessing the requirement of morphine. The requirement of morphine in current study was also similar between both arms.

Mucositis pain is associated with weight loss, delays and noncompliance with anticancer treatment [33, 34]. In the current study, the rate of weight loss and radiation compliance were similar between both arms. However, the proportion of patients receiving a cumulative dose of cisplatin of $200 \mathrm{mg} / \mathrm{m}^{2}$ or more was lower in the diclofenac arm. The probable reason for this is due to renal dysfunction caused by 
diclofenac. A cumulative dose of cisplatin of $200 \mathrm{mg} / \mathrm{m}^{2}$ or more is an important factor influencing efficacy outcomes in head and neck cancer [35].

The current study has its strengths and limitations. The strengths of this study are that it is a unique study evaluating the role of commonly prescribed systemic analgesics, provides data regarding compliance, longitudinal change of analgesic and quality of life, which is sparse in literature. The limitations are that the study was a single centre, open label study and there was no placebo arm in this study. Since there was no placebo arm, the impact of diclofenac and tramadol over placebo could not be studied. However, this aspect was considered at the time of conceptualisation of the study and it was considered unethical to deny patients of an analgesic. The study was conducted in a single centre. However, it led to a uniform treatment decision across both arms. The study was an open label study and hence both patients and physicians were aware about the study arm. However, the study methodology required patients to mark the pain on VAS and a change in analgesic was not permitted unless the prespecified VAS score criteria in the protocol were met, thus decreasing the probability of physician bias.

\section{Conclusion}

In this phase 3 study, evaluating diclofenac and tramadol for mucositis pain, analgesic efficacy of both analgesics was found to be similar but diclofenac was associated with a numerically statistically non-significant higher rate of renal dysfunction.

\section{List of abbreviations}

CTRT, Chemoradiation; NSAIDs, Non-steroidal anti-inflammatory drugs; AUC, Area under the curve; CTRI, Clinical Trial Registry of India; WHO, World Health Organization; TRAC, Tata Memorial Center Research Administration Council; ECOG PS, Eastern Cooperative Oncology Group Performance Status; VAS, Visual Analogue Scale; EORTC QLQ, European Organization for the Research and Treatment of Cancer Quality of Life Questionnaire; 3DCRT, Three-dimensional conformal radiation therapy.

\section{Acknowledgments}

The authors would like to thank the TRAC for funding this study.

Kumar Prabhash and Vijay Patil have full access to all the data in the study and take responsibility for the integrity of the data and the accuracy of the data analysis. Data analysis was conducted by Atanu Bhattacharjee, Vijay Patil and Kumar Prabhash.

\section{Conflicts of interest}

The authors declare the following financial interests/personal relationships which may be considered as potential competing interests:

Dr. Noronha reports grants from Dr. Reddy's Laboratories Inc., grants from Amgen, grants from Sanofi Aventis, outside the submitted work.

Dr. Prabhash reports grants from Biocon Ltd, grants from Dr. Reddy's Laboratories Inc., grants from Fresenius Kabi India Pvt Ltd, grants from Alkem Laboratories, grants from Natco Pharma Ltd, grants from BDR Pharmaceuticals Intl Pvt Ltd, grants from Roche Holding AG, outside the submitted work.

None of the other authors have anything to declare that may be considered as potential competing interests.

\section{Trial registration}

Clinical Trials Registry-India (CTRI): CTRI/2016/09/007302 (Registered on 23/09/2016) Trial Registered Prospectively. 


\section{Funding}

This work is supported by TRAC (Grant Number - not applicable). The funding agency had no role in design and conduct of the study, collection, management, analysis, and interpretation of the data, preparation, review or approval of the manuscript, and decision to submit the manuscript for publication.

\section{References}

1. Patil VM, Noronha V, and Joshi A, et al (2019) A randomized phase 3 trial comparing nimotuzumab plus cisplatin chemoradiotherapy versus cisplatin chemoradiotherapy alone in locally advanced head and neck cancer Cancer [Internet] 125(18) 3184-3197 https://doi. org/10.1002/cncr.32179 PMID: 31150120

2. Noronha V, Joshi A, and Patil VM, et al (2017) Once-a-week versus once-every-3-weeks cisplatin chemoradiation for locally advanced head and neck cancer: a phase III randomized noninferiority trial J Clin Oncol https://doi.org/10.1200/JC0.2017.35.15_suppl.6007 PMID: 29220295

3. Trotti A, Bellm LA, and Epstein JB, et al (2003) Mucositis incidence, severity and associated outcomes in patients with head and neck cancer receiving radiotherapy with or without chemotherapy: a systematic literature review Radiother Oncol 66(3) 253-262 https://doi. org/10.1016/S0167-8140(02)00404-8 PMID: 12742264

4. Vokurka S (2010) Oropharyngeal mucositis-pain management Klin Onkol 24(4) 278-280

5. Naidu MUR, Ramana GV, and Rani PU, et al (2004) Chemotherapy-induced and/or radiation therapy-induced oral mucositis-complicating the treatment of cancer Neoplasia 6(5) 423-431 https://doi.org/10.1593/neo.04169 PMID: 15548350 PMCID: 1531648

6. Lalla RV, Bowen J, and Barasch A, et al (2014) MASCC/ISOO clinical practice guidelines for the management of mucositis secondary to cancer therapy Cancer 120(10) 1453-1461 https://doi.org/10.1002/cncr.28592 PMID: 24615748 PMCID: 4164022

7. Blakaj A, Bonomi M, and Gamez ME, et al (2019) Oral mucositis in head and neck cancer: evidence-based management and review of clinical trial data Oral Oncol 95 29-34 https://doi.org/10.1016/j.oraloncology.2019.05.013 PMID: 31345391

8. Mallick S, Benson R, and Rath GK (2016) Radiation induced oral mucositis: a review of current literature on prevention and management Eur Arch Otorhinolaryngol 273(9) 2285-2293 https://doi.org/10.1007/s00405-015-3694-6

9. Christoforou J, Karasneh J, and Manfredi M, et al (2019) World workshop on oral medicine VII: non-opioid pain management of head and neck chemo/radiation-induced mucositis: a systematic review Oral Dis 25(Suppl 1) 182-192 https://doi.org/10.1111/odi.13074 PMID: 30811811

10. Sio TT, Le-Rademacher JG, and Leenstra JL, et al (2019) Effect of doxepin mouthwash or diphenhydramine-lidocaine-antacid mouthwash vs placebo on radiotherapy-related oral mucositis pain: the alliance A221304 randomized clinical trial JAMA 321(15) 1481-1490 https://doi.org/10.1001/jama.2019.3504 PMID: 30990550 PMCID: 6484809

11. Leenstra JL, Miller RC, and Qin R, et al (2014) Doxepin rinse versus placebo in the treatment of acute oral mucositis pain in patients receiving head and neck radiotherapy with or without chemotherapy: a phase III, randomized, double-blind trial (NCCTG-N09C6 [Alliance]) J Clin Oncol 32(15) 1571-1577 https://doi.org/10.1200/JCO.2013.53.2630 PMID: 24733799 PMCID: 4026580

12. Kakoei S, Pardakhty A, and Hashemipour MAS, et al (2018) Comparison the pain relief of amitriptyline mouthwash with benzydamine in oral mucositis J Dent 19(1) 34-40

13. Kostřica R, Rottenberg J, and Kvech J, et al (2002) Randomised, double-blind comparison of efficacy and tolerability of diclofenac mouthwash versus placebo in mucositis of oral cavity by radiotherapy J Clin Res 5(1) 1-15 
14. Elad S, and Yarom $N$ (2019) The search for an effective therapy and pain relief for oral mucositis JAMA 321(15) 1459-1461 https://doi. org/10.1001/jama.2019.3269 PMID: 30990535

15. Alfieri S, Ripamonti $\mathrm{Cl}$, and Marceglia S, et al (2016) Temporal course and predictive factors of analgesic opioid requirement for chemoradiation-induced oral mucositis in oropharyngeal cancer Head Neck 38(Suppl 1) E1521-E1527 https://doi.org/10.1002/hed.24272 PMID: 26849016

16. Mirabile A, Airoldi M, and Ripamonti C, et al (2016) Pain management in head and neck cancer patients undergoing chemo-radiotherapy: clinical practical recommendations Crit Rev Oncol Hematol 99 100-106 https://doi.org/10.1016/j.critrevonc.2015.11.010

17. Konopka-Filippow M, and Zabrocka E, et al (2015) Pain management during radiotherapy and radiochemotherapy in oropharyngeal cancer patients: single-institution experience Int Dent J 65(5) 242-248 https://doi.org/10.1111/idj.12181 PMID: 26362241

18. Miller E (2004) The World Health Organization analgesic ladder J Midwifery Womens Health 49(6) 542-545 https://doi.org/10.1016/j. jmwh.2004.08.021 PMID: 15544984

19. Anekar AA, and Cascella M (2021) WHO analgesic ladder StatPearls (FL: StatPearls Publishing)

20. Vadalouca A, Raptis E, and Moka E, et al (2012) Pharmacological treatment of neuropathic cancer pain: a comprehensive review of the current literature Pain Pract 12(3) 219-251 https://doi.org/10.1111/j.1533-2500.2011.00485.x

21. Glare P, Walsh D, and Sheehan D (2006) The adverse effects of morphine: a prospective survey of common symptoms during repeated dosing for chronic cancer pain Am J Hosp Palliat Care 23(3) 229-235 https://doi.org/10.1177/1049909106289068 PMID: 17060284

22. Clive DM, and Stoff JS (1984) Renal syndromes associated with nonsteroidal antiinflammatory drugs N Engl J Med 310(9) 563-572 https://doi.org/10.1056/NEJM198403013100905 PMID: 6363936

23. Garella S, and Matarese RA (1984) Renal effects of prostaglandins and clinical adverse effects of nonsteroidal anti-inflammatory agents Medicine 63(3) 165-181 https://doi.org/10.1097/00005792-198405000-00003 PMID: 6371441

24. Bhat ZY, Cadnapaphornchai P, and Ginsburg K, et al (2015) Understanding the risk factors and long-term consequences of cisplatin-associated acute kidney injury: an observational cohort study PLoS One 10(11) e0142225 https://doi.org/10.1371/journal.pone.0142225 PMID: 26556481 PMCID: 4640577

25. Lalla RV, Choquette LE, and Curley KF, et al (2014) Randomized double-blind placebo-controlled trial of celecoxib for oral mucositis in patients receiving radiation therapy for head and neck cancer Oral Oncol 50(11) 1098-1103 https://doi.org/10.1016/j.oraloncology.2014.08.001 PMID: 25151488 PMCID: 4856470

26. Emery P, Koncz T, and Pan S, et al (2008) Analgesic effectiveness of celecoxib and diclofenac in patients with osteoarthritis of the hip requiring joint replacement surgery: a 12-week, multicenter, randomized, double-blind, parallel-group, double-dummy, noninferiority study Clin Ther 30(1) 70-83 https://doi.org/10.1016/j.clinthera.2008.01.016 PMID: 18343244

27. Sullivan GM, and Feinn R (2012) Using effect size-or why the $p$ value is not enough J Grad Med Educ 4(3) 279-282 https://doi. org/10.4300/JGME-D-12-00156.1 PMCID: 3444174

28. Ang KK, Zhang Q, and Rosenthal DI, et al (2014) Randomized phase III trial of concurrent accelerated radiation plus cisplatin with or without cetuximab for stage III to IV head and neck carcinoma: RTOG 0522 J Clin Oncol 32(27) 2940-2950 https://doi.org/10.1200/ JCO.2013.53.5633 PMID: 25154822 PMCID: 4162493

29. Cooper JS, Pajak TF, and Forastiere AA, et al (2004) Postoperative concurrent radiotherapy and chemotherapy for high-risk squamouscell carcinoma of the head and neck N Engl J Med 350(19) 1937-1944 https://doi.org/10.1056/NEJMoa032646 PMID: 15128893 
30. Zsengellér ZK, Ellezian L, and Brown D, et al (2012) Cisplatin nephrotoxicity involves mitochondrial injury with impaired tubular mitochondrial enzyme activity J Histochem Cytochem 60(7) 521-529 https://doi.org/10.1369/0022155412446227 PMID: 22511597 PMCID: 3460350

31. Hörl WH (2010) Nonsteroidal anti-inflammatory drugs and the kidney Pharmaceuticals 3(7) 2291-2321 https://doi.org/10.3390/ ph3072291 PMID: 27713354 PMCID: 4036662

32. Malyszko J, Kozlowska K, and Kozlowski L, et al (2017) Nephrotoxicity of anticancer treatment Nephrol Dial Transplant 32(6) 924-936

33. Russo G, Haddad R, and Posner M, et al (2008) Radiation treatment breaks and ulcerative mucositis in head and neck cancer Oncologist 13(8) 886-898 https://doi.org/10.1634/theoncologist.2008-0024 PMID: 18701763

34. Elting LS, Cooksley CD, and Chambers MS, et al (2007) Risk, outcomes, and costs of radiation-induced oral mucositis among patients with head-and-neck malignancies Int J Radiat Oncol Biol Phys 68(4) 1110-1120 https://doi.org/10.1016/j.ijrobp.2007.01.053 PMID: 17398022

35. Ang KK (2004) Concurrent radiation chemotherapy for locally advanced head and neck carcinoma: are we addressing burning subjects? J Clin Oncol 22(23) 4657-4659 https://doi.org/10.1200/JCO.2004.07.962 PMID: 15534361 


\section{Supplementary appendix}

Supplementary Table 1.

\begin{tabular}{|c|c|c|c|c|c|}
\hline & Value & Standard error & Degrees of freedom & P-value & AIC \\
\hline \multicolumn{5}{|l|}{ Model1 } & \\
\hline Intercept & 3.65 & 0.43 & 1023 & 0.00 & \multirow[t]{3}{*}{3818.426} \\
\hline Arm & 0.23 & 0.27 & 126 & 0.38 & \\
\hline Visit & -.39 & 0.01 & 1023 & 0.00 & \\
\hline \multicolumn{5}{|l|}{ Model2 } & \\
\hline Intercept & 2.09 & 0.43 & 1024 & 0.00 & \multirow[t]{2}{*}{4521.805} \\
\hline Arm & 0.23 & 0.27 & 126 & 0.38 & \\
\hline
\end{tabular}

Supplementary Table 1- Result obtained through Linear Mixed Effect Model by maximum likelihood.AIC-Akaike Information Criterion

Supplementary Table 2.

\begin{tabular}{|l|l|c|c|c|}
\hline \multicolumn{1}{|c|}{ Variable } & \multicolumn{1}{c|}{ Type } & Odds ratio & 95\% Cl of the odds ratio & P-value \\
\hline \multicolumn{7}{|l|}{ The adjusted odds ratio for change in analgesic at 1 week } \\
\hline Arm & Binary & 2.329 & $0.69-7.855$ & 0.173 \\
\hline Site & Binary & 0.814 & $0.229-2.896$ & 0.75 \\
\hline T group & Binary & 0.728 & $0.19-2.784$ & 0.643 \\
\hline N group & Binary & 1.2227 & $0.382-3.943$ & 0.731 \\
\hline Baseline pain score & Binary & 0.417 & $0.136-1.281$ & 0.127 \\
\hline Age & Continuous & 1.037 & $0.975-1.103$ & 0.251 \\
\hline Tobacco use & Binary & 3.117 & $0.742-13.603$ & 0.119 \\
\hline The adjusted odds ratio for change in analgesic at end of chemoradiation & \\
\hline Arm & Binary & 1.612 & $0.749-3.471$ & 0.222 \\
\hline Site & Binary & 1.064 & $0.456-2.478$ & 0.887 \\
\hline T group & Binary & 0.737 & $0.293-1.856$ & 0.517 \\
\hline N group & Binary & 1.383 & $0.636-3.01$ & 0.413 \\
\hline Baseline pain score & Binary & 0.863 & $0.401-1.858$ & 0.707 \\
\hline Age & Continuous & 0.99 & $0.95-1.031$ & 0.621 \\
\hline Tobacco use & Binary & 3.402 & $1.067-10.847$ & 0.038 \\
\hline
\end{tabular}

Supplementary Table 2- Adjusted odds ratio for change in analgesic at 1 week and end of chemoradiation.Cl- Confidence interval. Site- Oral(reference) versus non-oral. T group- T1-T2 (reference) versusT3-T4. N group-N0-N1 (reference) versus N2-N3. Baseline pain score- below 5 versus 5-10 (reference). Arm- Tramadol( reference) versus Diclofenac. Age was a continuous variable. Tobacco use- present (reference) versus absent. 
Supplementary Table 3.

\begin{tabular}{|c|c|c|c|c|c|c|}
\hline Domain & & Value & $\begin{array}{l}\text { Standard } \\
\text { error }\end{array}$ & $\begin{array}{l}\text { Degree of } \\
\text { freedom }\end{array}$ & t-value & $\mathrm{P}$-value \\
\hline \multirow{2}{*}{$\begin{array}{l}\text { Pain } \\
\text { (HNPA) }\end{array}$} & Intercept & 41.68 & 2.48 & 399 & 16.75 & 0.00 \\
\hline & Tramadol & -3.41 & 3.58 & 113 & -0.95 & 0.34 \\
\hline \multirow{2}{*}{$\begin{array}{l}\text { Swallowing } \\
\text { (HNSW) }\end{array}$} & Intercept & 41.94 & 2.87 & 352 & 14.58 & 0.00 \\
\hline & Tramadol & -2.26 & 4.07 & 110 & -0.55 & 0.57 \\
\hline \multirow{2}{*}{$\begin{array}{l}\text { Speech problems } \\
\text { (HNSP) }\end{array}$} & Intercept & 42.53 & 2.85 & 354 & 14.90 & 0.00 \\
\hline & Tramadol & -2.09 & 4.07 & 110 & -0.51 & 0.60 \\
\hline \multirow{2}{*}{$\begin{array}{l}\text { Trouble with social } \\
\text { eating (HNSO) }\end{array}$} & Intercept & 36.82 & 2.96 & 356 & 12.42 & 0.00 \\
\hline & Tramadol & 2.22 & 4.27 & 112 & 0.52 & 0.60 \\
\hline \multirow{2}{*}{$\begin{array}{l}\text { Trouble with social } \\
\text { contact (HNSC) }\end{array}$} & Intercept & 35.32 & 3.55 & 263 & 9.94 & 0.00 \\
\hline & Tramadol & 0.45 & 5.07 & 98 & 0.08 & 0.92 \\
\hline \multirow{2}{*}{ Less sexuality (HNSX) } & Intercept & 36.82 & 2.96 & 356 & 12.42 & 0.00 \\
\hline & Tramadol & 2.22 & 4.27 & 112 & 0.52 & 0.60 \\
\hline \multirow{2}{*}{ Teeth (HNTE) } & Intercept & 35.32 & 3.55 & 263 & 9.94 & 0.00 \\
\hline & Tramadol & 0.45 & 5.07 & 98 & 0.08 & 0.92 \\
\hline \multirow{2}{*}{$\begin{array}{l}\text { Opening mouth } \\
\text { (HNOM) }\end{array}$} & Intercept & 57.64 & 4.73 & 151 & 12.16 & 0.00 \\
\hline & Tramadol & -7.19 & 6.48 & 65 & -1.10 & 0.27 \\
\hline \multirow{2}{*}{ Dry mouth (HNDR) } & Intercept & 44.96 & 3.54 & 107 & 12.66 & 0.00 \\
\hline & Tramadol & 3.63 & 4.84 & 70 & 0.74 & 0.45 \\
\hline \multirow{2}{*}{ Sticky saliva (HNSS) } & Intercept & 53.47 & 2.76 & 265 & 0.00 & 0.00 \\
\hline & Tramadol & -1.06 & 4.11 & 94 & -0.25 & 0.79 \\
\hline \multirow{2}{*}{ Coughing (HNCO) } & Intercept & 54.55 & 2.90 & 275 & 18.75 & 0.00 \\
\hline & Tramadol & -3.08 & 4.16 & 95 & -0.74 & 0.46 \\
\hline \multirow{2}{*}{ Felt ill (HNFI) } & Intercept & 56.85 & 2.80 & 330 & 20.25 & 0.00 \\
\hline & Tramadol & -3.76 & 3.99 & 105 & -0.94 & 0.34 \\
\hline \multirow{2}{*}{ Pain killers (HNPK) } & Intercept & 53.12 & 2.94 & 289 & 18.04 & 0.00 \\
\hline & Tramadol & -3.05 & 102 & 102 & -0.72 & 0.46 \\
\hline \multirow{2}{*}{$\begin{array}{l}\text { Nutritional supplement } \\
\text { s (HNNU) }\end{array}$} & Intercept & 52.17 & 2.86 & 303 & 18.21 & 0.00 \\
\hline & Tramadol & -2.09 & 4.08 & 100 & -0.51 & 0.60 \\
\hline \multirow{2}{*}{ Feeding tube (HNFE) } & Intercept & 33.33 & 0.34 & 281 & 95.64 & 0.00 \\
\hline & Tramadol & 0.95 & 0.51 & 103 & 1.84 & 0.06 \\
\hline \multirow{2}{*}{ Weight loss (HNWL) } & Intercept & 33.33 & 0.63 & 126 & 52.13 & 0.00 \\
\hline & Tramadol & 1.56 & 0.96 & 67 & 1.61 & 0.11 \\
\hline \multirow{2}{*}{ Weight gain (HNWG) } & Intercept & 33.33 & 0.67 & 119 & 49.06 & 0.00 \\
\hline & Tramadol & 1.99 & 1.09 & 54 & 1.81 & 0.07 \\
\hline
\end{tabular}


Supplementary Table 3 (Continued).

\begin{tabular}{|c|c|c|c|c|c|c|}
\hline \multirow{2}{*}{$\begin{array}{l}\text { Global health status } \\
\text { (QL2) }\end{array}$} & Intercept & 53.65 & 2.61 & 377 & 20.49 & 0.00 \\
\hline & Tramadol & 1.45 & 3.74 & 108 & 0.38 & 0.69 \\
\hline \multirow{2}{*}{$\begin{array}{l}\text { Physical functioning } \\
\text { (PF) }\end{array}$} & Intercept & 73.35 & 2.13 & 441 & 34.37 & 0.00 \\
\hline & Tramadol & -1.40 & 3.04 & 115 & -0.45 & 0.64 \\
\hline \multirow{2}{*}{ Role functioning (RF) } & Intercept & 80.09 & 2.48 & 420 & 32.25 & 0.00 \\
\hline & Tramadol & -0.73 & 3.53 & 114 & -0.20 & 0.83 \\
\hline \multirow{2}{*}{$\begin{array}{l}\text { Emotional functioning } \\
\text { (EF) }\end{array}$} & Intercept & 70.01 & 2.54 & 429 & 27.51 & 0.00 \\
\hline & Tramadol & 0.27 & 3.63 & 114 & 0.07 & 0.93 \\
\hline \multirow{2}{*}{$\begin{array}{l}\text { Cognitive functioning } \\
\text { (CF) }\end{array}$} & Intercept & 80.11 & 2.40 & 433 & 33.31 & 0.00 \\
\hline & Tramadol & -0.30 & 3.43 & 115 & -0.08 & 0.92 \\
\hline \multirow{2}{*}{ Social functioning (SF) } & Intercept & 80.30 & 2.43 & 405 & 32.96 & 0.00 \\
\hline & Tramadol & -4.70 & 3.49 & 114 & -1.34 & 0.18 \\
\hline \multirow{2}{*}{ Fatigue (FA) } & Intercept & 43.69 & 2.45 & 391 & 17.78 & 0.00 \\
\hline & Tramadol & -1.78 & 3.52 & 114 & -0.50 & 0.61 \\
\hline \multirow{2}{*}{$\begin{array}{l}\text { Nausea and vomiting } \\
\text { (NV) }\end{array}$} & Intercept & 31.87 & 2.40 & 268 & 13.23 & 0.00 \\
\hline & Tramadol & 3.86 & 3.32 & 98 & 1.16 & 0.24 \\
\hline \multirow[b]{2}{*}{ Pain (PA) } & Intercept & 40.85 & 2.49 & 357 & 16.37 & 0.00 \\
\hline & Tramadol & -1.85 & 3.58 & 112 & -0.51 & 0.60 \\
\hline \multirow{2}{*}{ Dyspnoea (DY) } & Intercept & 40.49 & 2.52 & 140 & 16.04 & 0.00 \\
\hline & Tramadol & 4.92 & 3.72 & 74 & 1.32 & 0.18 \\
\hline \multirow{2}{*}{ Insomnia (SL) } & Intercept & 48.71 & 2.728 & 198 & 17.85 & 0.00 \\
\hline & Tramadol & -0.75 & 4.02 & 93 & 0.18 & 0.85 \\
\hline \multirow{2}{*}{ Appetite loss (AP) } & Intercept & 51.87 & 2.63 & 294 & 19.68 & 0.00 \\
\hline & Tramadol & 0.00 & 3.70 & 104 & 0.00 & 0.99 \\
\hline \multirow{2}{*}{ Constipatio n (CO) } & Intercept & 46.08 & 2.68 & 178 & 17.15 & 0.00 \\
\hline & Tramadol & -1.47 & 3.83 & 86 & -0.38 & 0.70 \\
\hline \multirow{2}{*}{ Diarrhoea (DI) } & Intercept & 41.41 & 3.48 & 94 & 11.88 & 0.00 \\
\hline & Tramadol & 7.55 & 7.55 & 67 & 1.55 & 0.12 \\
\hline \multirow{2}{*}{$\begin{array}{l}\text { Financial difficulties } \\
\text { (FI) }\end{array}$} & Intercept & 57.65 & 3.29 & 230 & 17.48 & 0.00 \\
\hline & Tramadol & -1.90 & 4.65 & 94 & -0.40 & 0.68 \\
\hline
\end{tabular}

Supplementary Table 3- Quality of life analysis. The results are represented with diclofenac arm being considered as standard in relation with tramadol arm. 

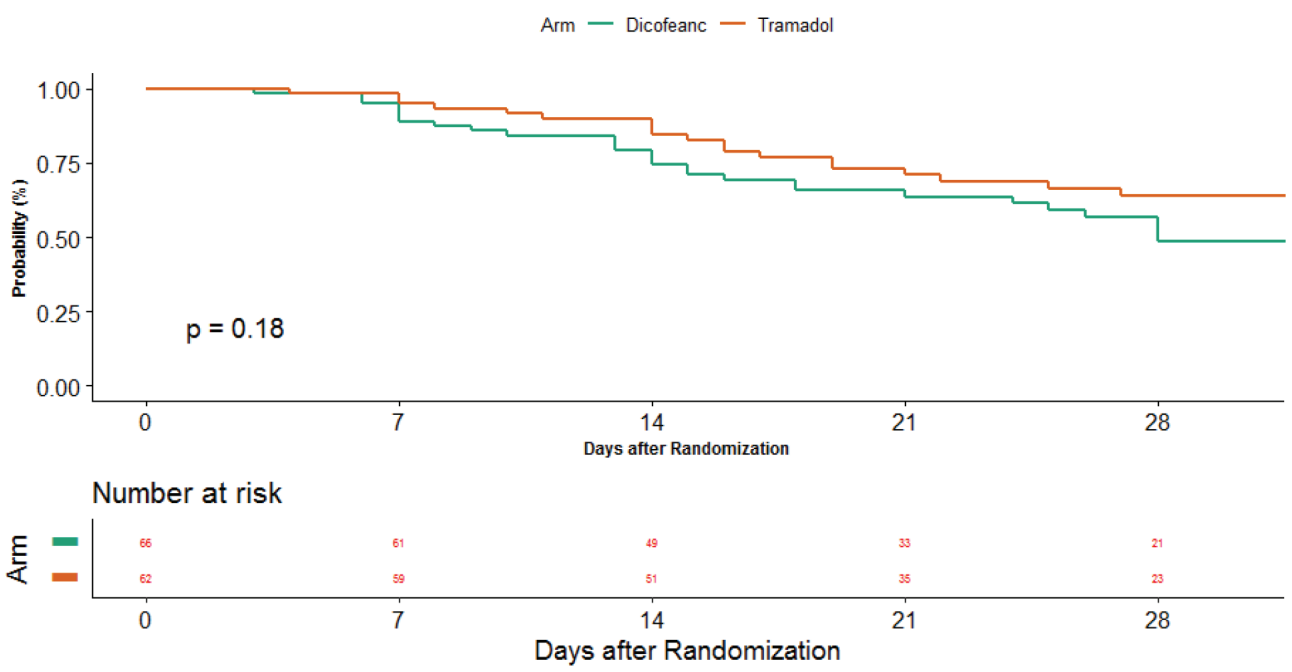

Supplementary Figure 1. Time to change of analgesic. 